\title{
Sudden loss of the deep brain stimulation effect with high impedance without macroscopic fracture: a case report and review of the published literature
}

\author{
This article was published in the following Dove Press journal: \\ Neuropsychiatric Disease and Treatment \\ 21 July 2015 \\ Number of times this article has been viewed
}

\author{
Hui-Jun Yang' \\ ji Young Yun ${ }^{2}$ \\ Young Eun Kim ${ }^{3}$ \\ Yong Hoon $\mathrm{Lim}^{4}$ \\ Han-Joon Kim ${ }^{5}$ \\ Sun Ha Paek ${ }^{4}$ \\ Beom S Jeon ${ }^{5}$ \\ 'Department of Neurology, \\ Ulsan University Hospital, Ulsan, \\ ${ }^{2}$ Department of Neurology, Ewha \\ Womans University Mokdong \\ Hospital, Seoul, ${ }^{3}$ Department of \\ Neurology, Hallym University \\ Sacred Heart Hospital, Anyang, \\ ${ }^{4}$ Department of Neurosurgery, \\ Seoul National University Hospital, \\ Seoul, ${ }^{5}$ Department of Neurology \\ and Movement Disorder Center, \\ Parkinson's Disease Study Group and \\ Neuroscience Research Institute, \\ Seoul National University Hospital, \\ Seoul, South Korea
}

\begin{abstract}
The number of deep brain stimulation (DBS) hardware complications has increased during the past decade. In cases of abnormally high lead impedance with no evidence of a macroscopic fracture, optimal treatment options have not yet been established. Here, we present the case of a 49-year-old woman with a 12-year history of Parkinson's disease who received bilateral subthalamic nucleus DBS in March 2006. The patient showed good control of parkinsonism until December 24, 2010, when she awoke with abrupt worsening of parkinsonian symptoms. At telemetric testing, lead impedances were found at $>2,000 \Omega$ in all four leads on the left side. Fracture of a lead or an extension wire was suspected. However, radiological screening and palpation revealed no macroscopic fracture. In June 2011, the implantable pulse generator (IPG) was changed under local anesthesia without any complications. Postoperatively, her parkinsonism immediately improved to the previous level, and the lead impedance readings by telemetry were also normalized. The disconnection of the neurostimulator connector block and the hybrid circuit board of the IPG was confirmed by destructive analysis. The present report illustrates that a staged approach that starts with simple IPG replacement can be an option for some cases of acute DBS effect loss with high impedance, when radiological findings are normal, thereby sparing the intact electrodes and extension wires.
\end{abstract}

Keywords: connector block, hardware complication, implantable neurostimulators, Parkinson's disease

\section{Introduction}

Deep brain stimulation (DBS) has become the established treatment of medically intractable movement disorders including Parkinson's disease, essential tremor, and dystonia. ${ }^{1-4}$ Consequently, the number of DBS hardware problems has increased during the past decade. ${ }^{2}$ DBS hardware consists of the following components: the implantable pulse generator (IPG), the electrode lead, and the extension wire. ${ }^{3}$ The IPG connector block which lies on the header block of the neurostimulator, provides the electrical contact between the IPG and the extension wire.

Lead impedance measurements by telemetry are being increasingly used as an initial diagnostic tool for DBS hardware failure., ${ }^{2,5}$ Abnormally high impedance indicates an open circuit, and palpation of the electrode wire and radiological screening are available to diagnose fractures in the electrode lead or the extension. ${ }^{3,5}$ Surgical revision should be performed if there is evidence of macroscopic breakage. Cases with no evidence of macroscopic fracture are more challenging, and optimal approach has not
Correspondence: Beom S Jeon Department of Neurology, Seoul National University Hospital,

I0I Daehak-Ro, Jongno-Gu, Seoul I I0-744, South Korea

Tel +82 220722876

Fax +82 220720839

Email brain@snu.ac.kr 
yet been established. ${ }^{1,2,6}$ Operative replacement of the whole DBS system should be considered; ${ }^{2}$ however, revision of the intracranial leads and the extension wires requires repeated stereotactic localization and reinsertion under general anesthesia, which may cause significant morbidity. ${ }^{7}$

This report describes a case of acute loss of the DBS effect presenting with abnormally elevated impedance and no evidence of macroscopic fracture, which was successfully addressed through neurostimulator replacement under local anesthesia. The report also presents a review of the relevant literature.

\section{Case report}

A 49-year-old woman with a 12-year history of Parkinson's disease received bilateral subthalamic nucleus DBS with a Soletra (Medtronic, Minneapolis, MN, USA) neurostimulator on March 27, 2006. Preoperatively, her unified Parkinson's disease rating scale (UPDRS) motor scores were 1.5 on medication and 16.5 off medication. She had severe dyskinesia more than $60 \%$ of the time while on medication. She was followed regularly, and showed good control of parkinsonism for a period of 5 years after surgery. In March 2009, her UPDRS motor scores were 4.5 with DBS stimulation and 37 without (Figure 1). The stimulation settings were 3.0 volts, 60 microseconds, $130 \mathrm{~Hz}$ for cathode 2 on the right side, and 2.4 volts, 60 microseconds, $130 \mathrm{~Hz}$ for cathodes 2 and 3 on the left side.

The patient was well until December 24, 2010, when she awoke with an abrupt worsening of her parkinsonism with no clear precipitant. Five days later, she visited our movement disorder center. On testing, the battery voltage levels were intact. Impedances were increased to $>2,000 \Omega$ in all four lead contacts on the left side, indicative of an open circuit. The results did not change in multiple body positions. ${ }^{5}$
Her condition failed to improve with medication (levodopa/ carbidopa $375 \mathrm{mg}$ /day; ropinirole $2 \mathrm{mg}$ /day; and amantadine $300 \mathrm{mg}$ /day). A fractured electrode lead or extension wire was suspected. However, a complete examination and radiological study revealed no macroscopic fracture.

In the telemetry, normal communication between the IPG and the programmer device was possible, and power-on reset was not found. ${ }^{8}$ In addition, we found no evidence of a broken extension or broken leads. Following these findings, we presumed that a dysfunction of the IPG connector block which makes electrical contacts and secures the extension wires with setscrews, caused the acute DBS effect loss with concurrent high impedance, and we decided to address the IPG first.

Prior to reoperation, her UPDRS motor scores with DBS stimulation were 34 with medication and 30 without (Figure 1). The scores without stimulation were 48 and 45 , respectively. On June 29, 2011, the IPG was replaced under local anesthesia without any complications. Postoperatively, the patient's parkinsonian symptoms immediately improved under the same neurostimulator settings. The lead impedance readings on the left side were normalized. The extracted neurostimulator showed no visible signs of deformity. When tested with an oscilloscope at 1,000- $\Omega$ load impedance, the neurostimulator could produce stimulation waveforms. The destructive analysis by the manufacturer revealed that the case feed-through wire was lifted on the hybrid side, and this finding was consistent with the disconnection between the IPG hybrid circuit board and the connector block of the IPG header.

During a follow-up period of 4 months with amantadine at $300 \mathrm{mg} /$ day, no recurrence of parkinsonian symptoms or high impedance measurements were reported. On November 2, 2011, her UPDRS motor scores were 11 with DBS stimulation and 34 without (Figure 1). In the 2 years after

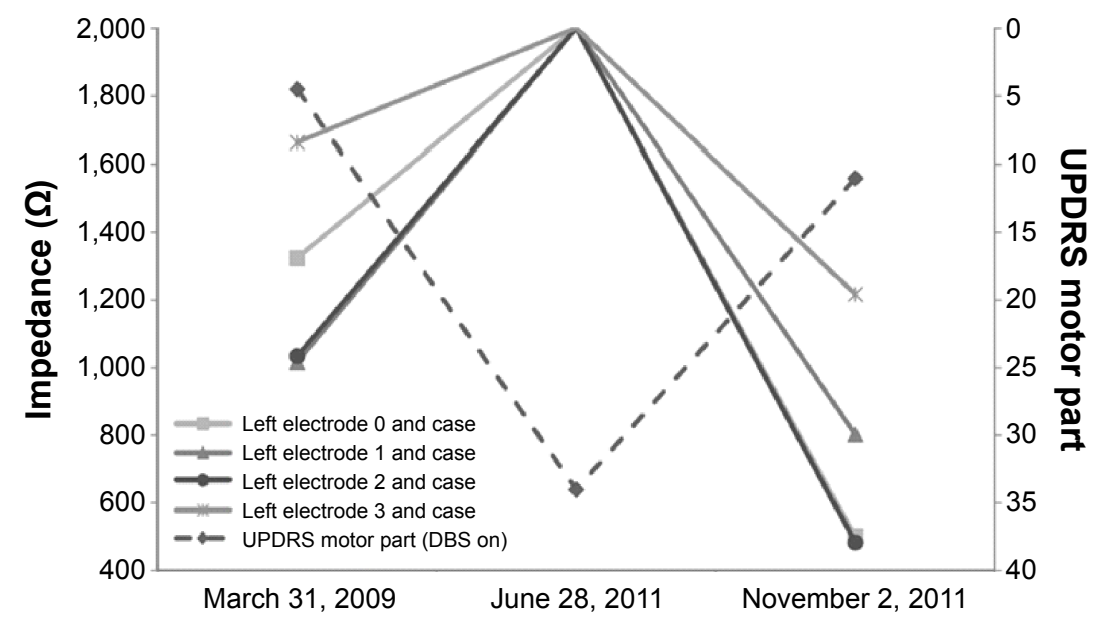

Figure I Changes in lead impedances and UPDRS motor part scores before and after neurostimulator replacement. Abbreviations: DBS, deep brain stimulation; UPDRS, unified Parkinson's disease rating scale. 
revision, her parkinsonism was well-controlled with subthalamic nucleus DBS, and her UPDRS motor scores were 15 (DBS on) and 47 (DBS off) on March 28, 2013.

\section{Discussion}

In evaluating the hardware-related complications of DBS, it is useful to consider the electrode leads, the extension wires, and the IPGs as a system. Dysfunction of any one component can lead to system failure. Lead impedance diagnostics by telemetry has been suggested as a screening tool for DBS system integrity. ${ }^{2,3,9}$ Low impedance indicates a potential short-circuit state, and abnormally high impedance associates with an electrical open-circuit state. For the latter cases, palpation and radiological screening are available to diagnoses a lead fracture or an extension wire fracture.

Although movement disorder clinicians might expect that palpation and radiological screening discover any hardware fracture or disconnection point, this is sometimes not the case. ${ }^{10,11}$ According to the literature, the fracture location cannot be determined after complete examination and radiological study in $14.3 \%-25 \%$ of suspected open-circuit cases., ${ }^{3,10}$ There have been limited reports of improvement after surgical revision, ${ }^{5,9,11-15}$ reprogramming, ${ }^{10}$ or prolonged lead activation (conditioning), ${ }^{16}$ so the management of these hardware complications remains elusive. ${ }^{1,17}$ Previously reported cases are summarized in Table $1 .^{5,10-16}$ Although operative replacement of whole DBS system is a definite treatment, ${ }^{2}$ this treatment is, however, not exempt from morbidity and mortality. Some authors have recommended to address the extension wire first, and to measure intraoperative lead impedance during surgery (Figure 2). ${ }^{1,6}$

In the present report, the treating clinicians faced the same kind of challenge. Our patient showed a sole impedance increase to $>2,000 \Omega$ without any sign of macroscopic fracture according to palpation and radiological study. Telemetric communication between the IPG and the programming device was intact. We presumed that the IPG connector block dysfunction had caused the sudden loss of the DBS effect in this patient; ${ }^{8,18}$ a staged approach including conventional IPG replacement under local anesthesia was followed. The problem resolved thereafter, indicating a defect in the IPG itself or in the connection between the extension wire and the IPG. The disconnection of the IPG connector block and the hybrid circuit board of the neurostimulator was confirmed after a destructive analysis which was performed by the manufacturer. No reoccurrence of parkinsonism or high impedance measurements have emerged from regular monitoring during the postoperative follow-up period, which suggests that the electrode lead and the extension wire are intact. Indeed, connector block dysfunctions of cardiac pacemakers which are stimulating devices similar to the IPGs, have been widely reported to be the cause of device failures with high lead impedance and open circuits. ${ }^{18,19}$

In cases of abnormally increased lead impedance and open circuit without a macroscopic fracture, the optimal treatment options are still not established. A proposed algorithm for assessing and troubleshooting those specific cases is presented in Figure 2. ${ }^{1,2,6,17}$ Conventional IPG replacement under

Table I Summary of clinical features of eleven cases of abnormally high impedance measurement without macroscopic fracture (ten cases from the literature; one case from the present report)

\begin{tabular}{|c|c|c|c|c|c|c|c|}
\hline Case & References & $\begin{array}{l}\text { Age } \\
\text { (years) }\end{array}$ & $\begin{array}{l}\text { DBS } \\
\text { indication }\end{array}$ & $\begin{array}{l}\text { Time to complication } \\
\text { and debut }\end{array}$ & $\begin{array}{l}\text { Impedance } \\
(\Omega)\end{array}$ & $\begin{array}{l}\text { X-ray or other } \\
\text { test findings }\end{array}$ & Action taken \\
\hline I & Farris et $\mathrm{al}^{5}$ & 63 & PD & $\begin{array}{l}2 \text { years, sudden loss of } \\
\text { tremor control }\end{array}$ & $>2,000$ & $\begin{array}{l}\text { Did not reveal } \\
\text { hardware deformities }\end{array}$ & $\begin{array}{l}\text { Electrode lead wire } \\
\text { replacement }\end{array}$ \\
\hline 2 & Guridi et al $^{10}$ & 56 & PD & $\begin{array}{l}33 \text { months, progressive } \\
\text { loss of clinical benefit }\end{array}$ & $>4,000$ & $\begin{array}{l}\text { No disruption (X-ray } \\
\text { findings) }\end{array}$ & IPG reprogramming \\
\hline 3 & Joint et al' & ND & ND & 7 months & High & $\begin{array}{l}\text { Did not reveal } \\
\text { hardware deformities }\end{array}$ & $\begin{array}{l}\text { Fractured lead } \\
\text { replacement }\end{array}$ \\
\hline 4 & Constantoyannis et $\mathrm{al}^{12}$ & ND & ND & $\begin{array}{l}\text { ND, sudden loss of DBS } \\
\text { benefit }\end{array}$ & $>2,000$ & $\begin{array}{l}\text { Did not reveal } \\
\text { hardware deformities }\end{array}$ & $\begin{array}{l}\text { Extension wire } \\
\text { replacement }\end{array}$ \\
\hline 5 & Alex Mohit et al ${ }^{13}$ & 70 & PD & $\begin{array}{l}32 \text { months, loss of } \\
\text { tremor control }\end{array}$ & ND & $\begin{array}{l}\text { No disruption (X-ray } \\
\text { findings) }\end{array}$ & $\begin{array}{l}\text { Electrode lead wire } \\
\text { replacement }\end{array}$ \\
\hline 6 & de Andrade et al $^{14}$ & 62 & PD & I year & $>4,000$ & $\begin{array}{l}\text { No disconnections } \\
\text { or breakages (X-ray } \\
\text { and CT findings) }\end{array}$ & $\begin{array}{l}\text { Electrode lead wire } \\
\text { replacement }\end{array}$ \\
\hline 7-9 & Baizabal Carvallo et al ${ }^{15}$ & ND & ND & ND & $>2,000$ & $\begin{array}{l}\text { No fracture was } \\
\text { observed by X-ray }\end{array}$ & $\begin{array}{l}\text { Surgical replacements } \\
\text { of the fractured leads }\end{array}$ \\
\hline 10 & Jaggi and Baltuch ${ }^{16}$ & 65 & PD & Immediate after revision & $>4,000$ & Okay & $\begin{array}{l}\text { Prolonged lead } \\
\text { activation }\end{array}$ \\
\hline II & Present case & 49 & PD & $\begin{array}{l}5 \text { years, sudden loss of } \\
\text { DBS benefit }\end{array}$ & $>2,000$ & $\begin{array}{l}\text { Did not reveal } \\
\text { hardware deformities }\end{array}$ & IPG replacement \\
\hline
\end{tabular}

Abbreviations: CT, computed tomography; DBS, deep brain stimulation; IPG, implantable pulse generator; ND, no description; PD, Parkinson's disease. 


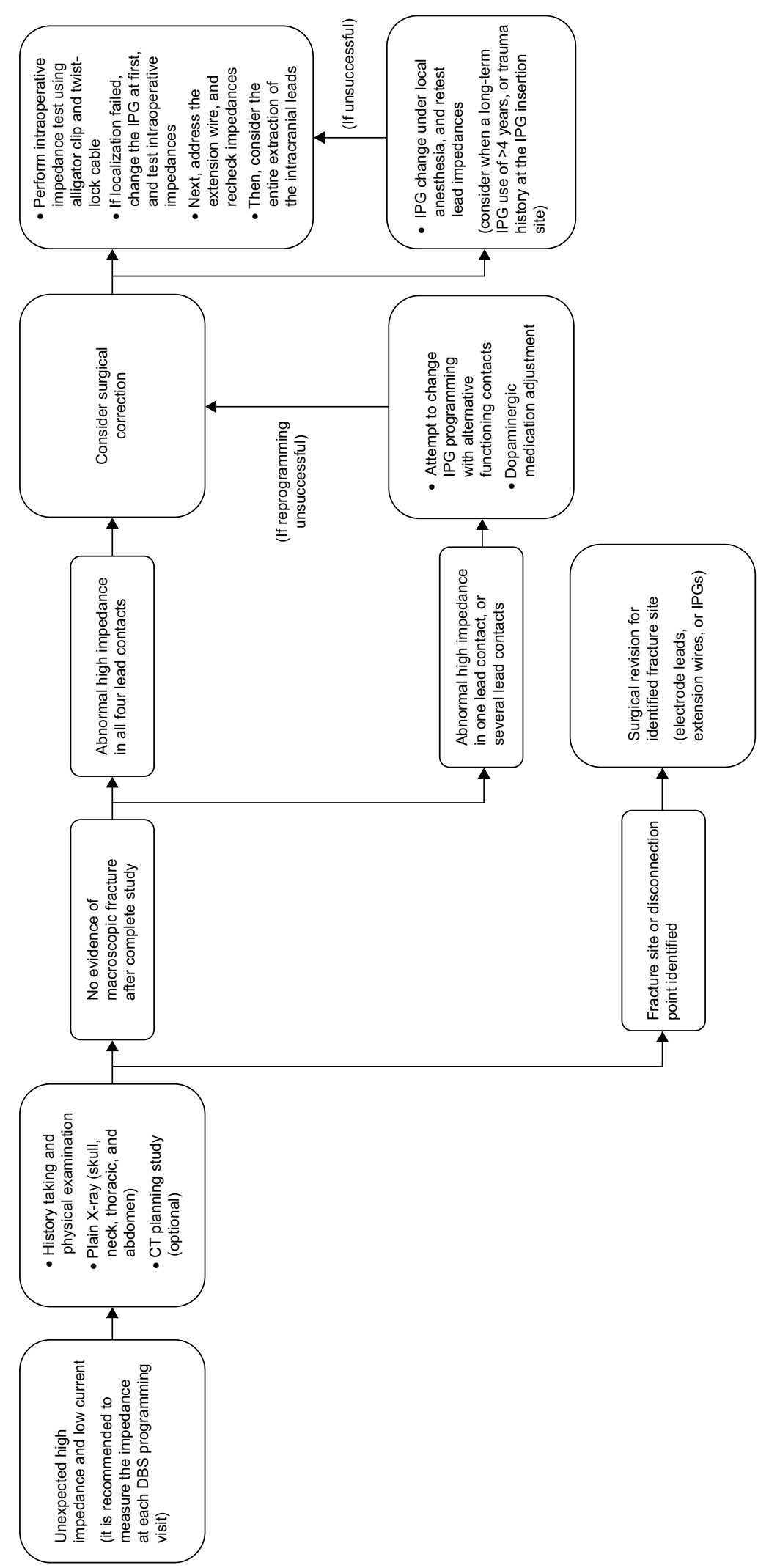


local anesthesia is simple, and it can be performed in cases with unexplained high lead impedance before the decision is made to replace the electrode leads or extension wires. This approach may be preferred in patients with either a long-term IPG use of more than 4 years, ${ }^{20}$ or a trauma history at the neurostimulator insertion site (Figure 2) ${ }^{8,15}$ On the other hand, some cautionary notes should be sounded. The neurostimulator replacement procedure can cause several complications, such as infection or damage to the lead extender. If there is no clinical improvement after the IPG change, the extension wire replacement with a direct intraoperative testing of the intracranial leads during surgery should be the next step of management (Figure 2). 1,6,14 This staged approach can spare intact leads and extensions, and avoid unnecessary replacements and complications.

\section{Acknowledgment}

This study was supported by a Grant No.04-2011-0920 from the Seoul National University Hospital Research Fund.

\section{Author contributions}

HJY designed and drafted the article. HJY, SHP, and BSJ were clinicians in charge of the clinical care of the patient. JYY, YEK, YHL, and HJK contributed to the literature search. HJY, JYY, YEK, and YHL conducted the acquisition and interpretation of data. YEK, JYY, HJK, SHP, and BSJ participated in the design of the paper and reviewed the article. All authors contributed toward data analysis, drafting and revising the paper and agree to be accountable for all aspects of the work.

\section{Disclosure}

The authors report no conflicts of interest in this work.

\section{References}

1. Okun MS, Rodriguez RL, Foote KD, et al. A case-based review of troubleshooting deep brain stimulator issues in movement and neuropsychiatric disorders. Parkinsonism Relat Disord. 2008;14(7):532-538.

2. Baizabal Carvallo JF, Simpson R, Jankovic J. Diagnosis and treatment of complications related to deep brain stimulation hardware. Mov Disord. 2011;26(8):1398-1406.

3. Shils JL, Alterman RL, Arle JE. Deep brain stimulation fault testing. In: Tarsy D, Vitek JL, Starr PA, Okun MS, editors. Deep Brain Stimulation in Neurological and Psychiatric Disorders. Totowa: Humana Press; 2008:473-494.
4. Chopra A, Klassen BT, Stead M. Current clinical application of deep-brain stimulation for essential tremor. Neuropsychiatr Dis Treat. 2013;9:1859-1865.

5. Farris S, Vitek J, Giroux ML. Deep brain stimulation hardware complications: the role of electrode impedance and current measurements. Mov Disord. 2008;23(5):755-760.

6. Morishita T, Foote KD, Burdick AP, et al. Identification and management of deep brain stimulation intra- and postoperative urgencies and emergencies. Parkinsonism Relat Disord. 2010;16(3):153-162.

7. Schwalb JM, Riina HA, Skolnick B, Jaggi JL, Simuni T, Baltuch GH Revision of deep brain stimulator for tremor. Technical note. J Neurosurg. 2001;94(6):1010-1012.

8. Alesch F. Sudden failure of dual channel pulse generators. Mov Disord. 2005;20(1):64-66.

9. Farris S, Giroux ML. Lead wire fracture associated with normal therapeutic impedance measurements in a patient with a kinetra neurostimulator. Neuromodulation. 2010;13(1):65-67.

10. Guridi J, Rodriguez-Oroz MC, Alegre M, Obeso JA. Hardware complications in deep brain stimulation: electrode impedance and loss of clinical benefit. Parkinsonism Relat Disord. 2012;18(6):765-769.

11. Joint C, Nandi D, Parkin S, Gregory R, Aziz T. Hardware-related problems of deep brain stimulation. Mov Disord. 2002;17 Suppl 3:S175-S180.

12. Constantoyannis C, Berk C, Honey CR, Mendez I, Brownstone RM. Reducing hardware-related complications of deep brain stimulation. Can J Neurol Sci. 2005;32(2):194-200.

13. Alex Mohit A, Samii A, Slimp JC, Grady MS, Goodkin R. Mechanical failure of the electrode wire in deep brain stimulation. Parkinsonism Relat Disord. 2004;10(3):153-156.

14. de Andrade DC, Gurruchaga JM, Jarraya B, et al. Paroxysmal positive symptoms caused by hardware malfunctioning in deep brain stimulation. Brain Stimul. 2010;3(1):61-62.

15. Baizabal Carvallo JF, Mostile G, Almaguer M, Davidson A, Simpson R, Jankovic J. Deep brain stimulation hardware complications in patients with movement disorders: risk factors and clinical correlations. Stereotact Funct Neurosurg. 2012;90(5):300-306.

16. Jaggi JL, Baltuch GH. Deep brain stimulation inactivity can produce unexpected high electrode impedances when reactivated, leading to a false conclusion of wire fracture. Stereotact Funct Neurosurg. 2005; 83(5-6):187-189.

17. Medtronic. DBS Information about impedances. Minneapolis (MN): Medtronic, Inc.; 2014. Available from: http:/www.medtronic.co.kr/ wcm/groups/mdtcom_sg/@mdt/@neuro/documents/documents/ dbs-mri-impedances.pdf. Accessed June 1, 2015.

18. Braunschweig F, Boriani G, Bauer A, et al. Management of patients receiving implantable cardiac defibrillator shocks: recommendations for acute and long-term patient management. Europace. 2010;12(12): 1673-1690.

19. Haghjoo M. Pacing system malfunction: evaluation and troubleshooting. In: Das MK, editor. Modern Pacemakers-Present and Future. Rijeka: InTech; 2011:367-380.

20. Mehanna R, Wilson KM, Cooper SE, Machado AG, Fernandez HH. Clinical and programming pattern of patients with impending deep brain stimulation power failure: a retrospective chart review. Journal of Clinical Movement Disorders. 2014;1(1):6.
Neuropsychiatric Disease and Treatment

\section{Publish your work in this journal}

Neuropsychiatric Disease and Treatment is an international, peerreviewed journal of clinical therapeutics and pharmacology focusing on concise rapid reporting of clinical or pre-clinical studies on a range of neuropsychiatric and neurological disorders. This journal is indexed on PubMed Central, the 'PsycINFO' database and CAS,

\section{Dovepress}

and is the official journal of The International Neuropsychiatric Association (INA). The manuscript management system is completely online and includes a very quick and fair peer-review system, which is all easy to use. Visit http://www.dovepress.com/testimonials.php to read real quotes from published authors. 